\title{
Review of Applied Anatomy, Hemodynamics, and Endovascular Management of Ectopic Varices
} \author{
Mohammed Rafeeque P. K. ${ }^{4}$ \\ ${ }^{1}$ Interventional Radiology Subdivision, Department of Radiology, \\ Geetanjali Medical College \& Hospital, Udaipur, Rajasthan, India \\ 2 Medical Trust Hospital, Cochin, Kerala, India \\ ${ }^{3}$ Government Medical College, Kozhikode, Kerala, India \\ ${ }^{4}$ Meitra Hospital, Kozhikode, Kerala, India
}

Sitaram Barath ${ }^{1}$ Dharav Kheradia ${ }^{2}$ Shakti Parvathy Gopalkrishnan ${ }^{2}$ Rahul K. R. ${ }^{3}$
Address for correspondence Sitaram Barath, MD, Interventional Radiology Subdivision, Department of Radiology, AS-1 Geetanjali University Campus, Hiranmagri Extension, Manvakhera NH-8 Bypass, Near Eklingpura Chouraha, Udaipur, Rajasthan 313002, India (e-mail: barath.sitaram@gmail.com).

J Clin Interv Radiol ISVIR 2022;6:106-118.

\begin{abstract}
Keywords

- ectopic varices

- BRTO

- BATO

Portal hypertension leads to the opening up of collateral pathways to bypass the occlusion or resistance in the portal system. Ectopic varices are formed by such collaterals at many various sites along the gastrointestinal tract other than the usual location, that is, gastroesophageal region. Early diagnosis of ectopic varices needs strong clinical suspicion and contrast-enhanced computed tomography scan as endoscopy may often fail to pinpoint a source. In contrast to gastric varices where the understanding of the disease, as well as endovascular management, is widely studied and documented, the same is not true for ectopic varices due to low incidence. Understanding the applied anatomy and hemodynamic classification is important to decide the most suitable therapy. Interventional radiological procedures are aimed at either decompressing the varices or obliterating them and depend on the patency of the portal system, underlying etiology, and local expertise.
\end{abstract}

\section{Introduction}

Cirrhosis and extrahepatic portal venous obstruction (EHPVO) lead to the opening up of collateral pathways to bypass the portal occlusion or resistance. ${ }^{1,2}$ These collaterals could be either portosystemic or portoportal. These collaterals enlarge and form varices. The usual location of varices is the gastroesophageal region.

Ectopic varices are formed by such collaterals at many different sites along the gastrointestinal (GI) tract other than the usual location. ${ }^{3}$ Various reported sites of ectopic varices are described in -Table $\mathbf{1}{ }^{4}$

The understanding of gastric varices and their endovascular management is widely studied and documented; the same is not true for ectopic varices due to low incidence.

published online July 6, 2021
DOI https://doi.org/ 10.1055/s-0041-1730868. ISSN 2457-0214.
In this review article, we will try to discuss the applied anatomy, hemodynamics, and endovascular management of ectopic varices.

\section{Incidence and Prevalence}

As a small fraction of ectopic varices become symptomatic and are often underreported, the true incidence is undetermined. ${ }^{5}$ In a nationwide Japanese survey conducted by Watanabe et al, the incidence of ectopic varices at different location was duodenal (57\%), small intestinal (6.4\%), colonic (3.5\%), rectal (44.5\%), biliary (4.6\%), anastomotic (5.8\%), stomal (1.7\%), and diaphragm (0.6\%). The primary modality to diagnose the ectopic varices was endoscopy and a computed tomography (CT) scan was done whenever
(C) 2021. Indian Society of Vascular and Interventional Radiology. All rights reserved.

This is an open access article published by Thieme under the terms of the Creative Commons Attribution-NonDerivative-NonCommercial-License, permitting copying and reproduction so long as the original work is given appropriate credit. Contents may not be used for commercial purposes, or adapted, remixed, transformed or built upon. (https://creativecommons.org/ licenses/by-nc-nd/4.0/)

Thieme Medical and Scientific Publishers Pvt. Ltd., A-12, 2nd Floor, Sector 2, Noida-201301 UP, India 
Table 1 Sites of ectopic varices

\begin{tabular}{|l|l|}
\hline Luminal & Extraluminal \\
\hline Isolated gastric varices & Intraperitoneal \\
\hline Duodenum & Retroperitoneal \\
\hline Jejunum & Umbilicus \\
\hline Ileum & Around the falciform ligament \\
\hline Colon & Gallbladder and biliary tree \\
\hline Rectum and anal canal & Perisplenic \\
\hline Peristomal & Right diaphragm \\
\hline & Ovary \\
\hline & Vagina \\
\hline
\end{tabular}

required. About $5 \%$ of the variceal bleed is caused by ectopic varices. $^{6}$

\section{Etiology}

Portal hypertension secondary to liver cirrhosis is the most common underlying cause followed by the EHPVO, splenic vein thrombosis (secondary to pancreatitis/malignancy), or superior mesenteric vein (SMV) thrombosis. Some other underlying causes include pancreatic or gastric malignancy, liver metastasis, congenital hepatic fibrosis, and biliary stricture. In a patient with old abdominal surgery, ectopic varices can develop at the site of adhesions. ${ }^{3,4,6}$

Some congenital or familial conditions can cause colonic varices without portal hypertension. ${ }^{7-9}$

\section{Pathophysiology}

Portosystemic collaterals are at higher resistance than the portal circulation. Development of portal hypertension leads to shunting of blood through these collaterals. These collaterals enlarge and form varices.

The location and development of ectopic varices depend on a few factors. Generalized portal hypertension does not cause all ectopic varices. Additional locoregional hemodynamic factors also contribute. These locoregional hemodynamic factors include (1) visceral vein stenosis or occlusion (splenic vein, mesenteric vein, or portal vein), (2) postinflammatory and postoperative adhesions and scarring, (3) postoperative altered anatomy, and (4) occlusion of portosystemic shunts, for example, post-balloon-occluded retrograde transvenous obliteration (BRTO). Based on this, the ectopic varices can be divided into the nonocclusive type and occlusive type.

Ectopic varices are "true veins" histologically, have thicker walls, bigger diameter, and higher wall tension. Because of this, ectopic varices have four times more risk of bleeding compared with esophageal varices. ${ }^{10}$ Bleeding is often arduous to control and can be fatal in $40 \%{ }^{11}$ Ectopic varices bleed at low portosystemic gradients in more than half the cases. ${ }^{12}$ Ectopic portosystemic varices/collaterals not only lead to variceal bleed but may also manifest as hepatic encephalopathy.

\section{Applied Venous Anatomy}

Knowledge of afferent and efferent of a portosystemic shunt is of paramount importance to plan endovascular management. -Fig. 1 shows important portosystemic collaterals. Before we get on with venous anatomy related to specific sites of ectopic varices, we must understand here that the afferent is formed by a tributary of the portal vein and efferent in many cases by the vein of Retzius.

Veins of Retzius are a group of veins located in the abdomen which joins the inferior vena cava (IVC) with the SMV or inferior mesenteric vein (IMV). The veins of Retzius pathways get their name depending on anastomosing vein such as "mesenteric-gonadal, mesenteric-caval, mesentericrenal, or mesenteric-iliac." The veins of Retzius are frequently undilated and may not be well appreciated. ${ }^{13}$

\section{Duodenal Varices}

Duodenal varices are 1 to $3 \%$ of all varices. ${ }^{14}$ Compared with esophageal varices, duodenal varices are smaller, shorter, and deeper in location, hence their bleeding incidence is less. The paraduodenal varices connect with submucosal duodenal varices through perforators. Submucosal duodenal varices if visible on endoscopy have higher chances of bleeding as compared with if not visible. ${ }^{15,16}$

Afferents-There are four small pancreaticoduodenal veins, namely, posterior superior pancreaticoduodenal vein, anterior superior pancreaticoduodenal vein, posterior inferior pancreaticoduodenal vein, and anterior inferior pancreaticoduodenal vein. The superior and inferior veins can anastomose and form an arcade which is usually anterior but rarely can be posterior.

The posterior superior pancreaticoduodenal vein joins the portal vein. The anterior superior pancreaticoduodenal and the anterior inferior and posterior inferior pancreaticoduodenal veins join either the SMV directly or one of its tributaries, namely, gastrocolic trunk or the first jejunal trunk. This multiplicity of communications can make any vessel contributes to the collateral pathway ${ }^{13,17}$ (-Fig. 2).

Efferents-The efferents can be either via portosystemic collaterals or portoportal collaterals.

\section{Portosystemic Collaterals}

In cirrhosis, efferents start at the second or third part of the duodenum and have hepatofugal flow through retroperitoneal veins of Retzius, namely, right renal vein, right gonadal vein, right adrenal vein, or right inferior phrenic vein into the IVC. Another pathway is the subcostal vein and ascending lumbar vein via the azygos pathway into the superior vena cava. $^{18}$

\section{Portoportal Collaterals}

In extrahepatic portal vein obstruction, efferent starts at the first part of the duodenum and flow hepatopetally through portoportal collaterals. ${ }^{19}$ Portoportal collaterals can be formed by existing venous plexuses around the common bile duct $(\mathrm{CBD})$ or by portal vein remnant above the 


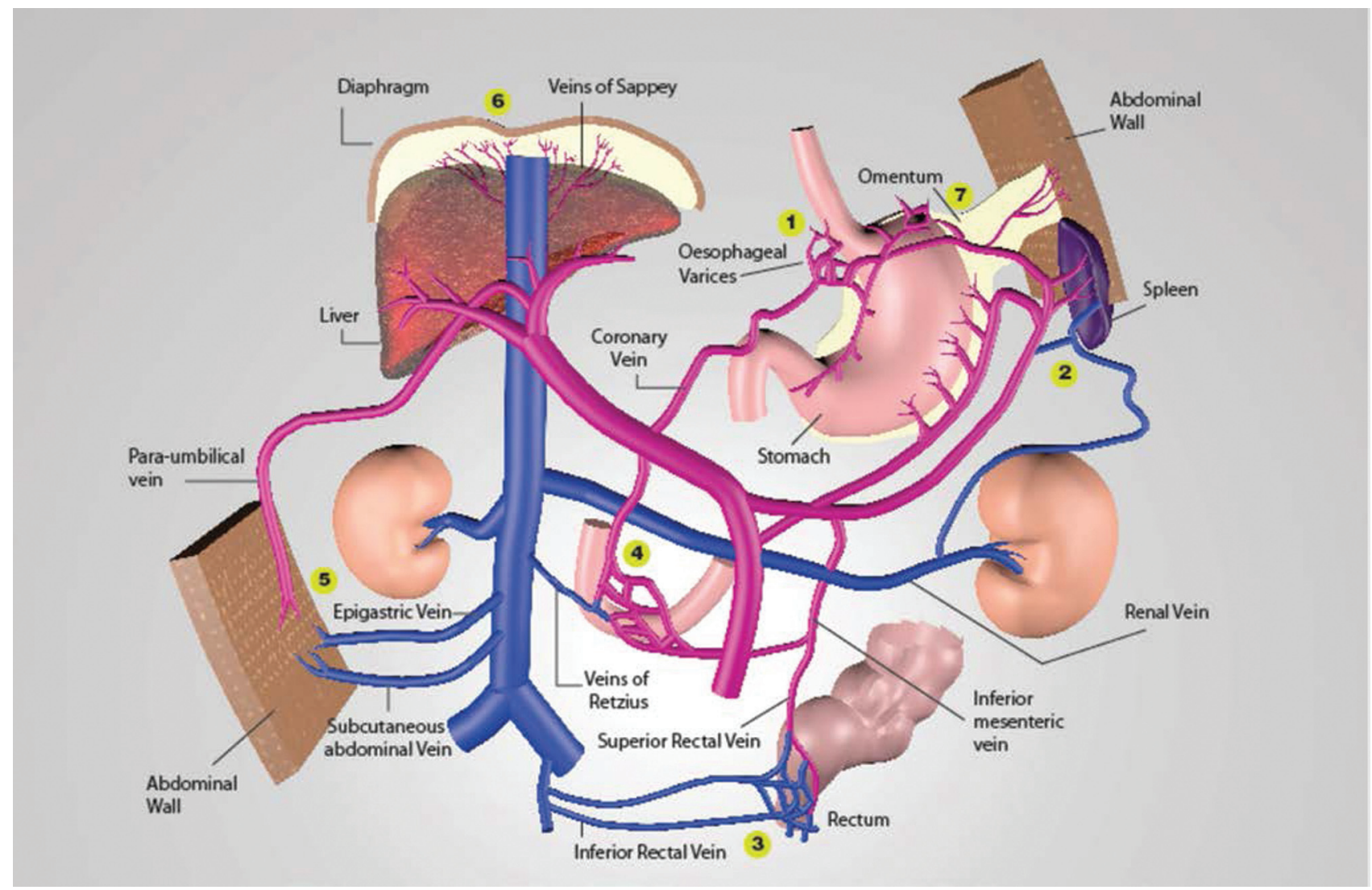

Fig. 1 Different sites of portosystemic anastomosis which can form varices. 1, lower esophagus; 2, splenorenal; 3, rectum; 4, retroperitoneal via the vein of Retzius; 5 , umbilical and paraumbilical; 6, bare area of the liver; 7, omentum.

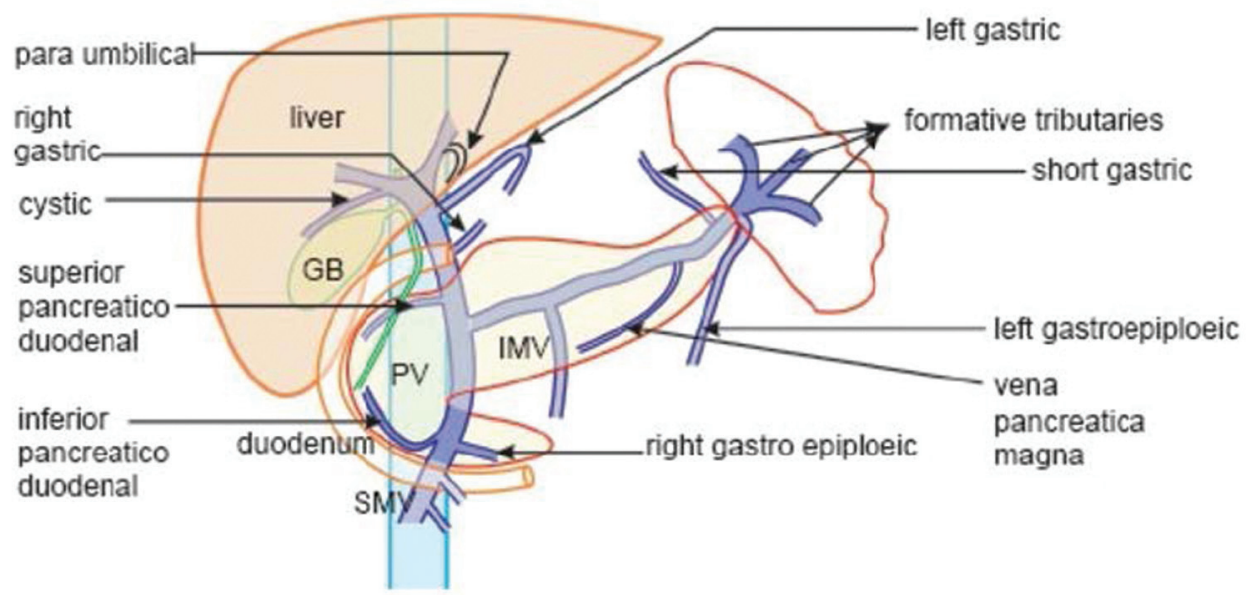

Fig. 2 Important splanchnic circulation anatomy in relation to the duodenum. Because of the multiplicity of communications between these veins, any vein can contribute to varices formation. (Reproduced with permission from Sharma et al. ${ }^{13}$ )

obstructed portal system. ${ }^{20}$ Collaterals in EHPVO are again described in detail in biliary varices.

\section{Small Bowel Varices}

These are often seen in patients with portal hypertension, chronic SMV thrombosis, or with a history of abdominal surgery. Postoperative adhesions between the surface of the bowel and the abdominal wall, coupled with portal hyper- tension allow varices development. "A triad of portal hypertension, hematochezia without hematemesis, and prior abdominal surgery characterizes hemorrhage from small bowel varices." ${ }^{21}$ Small bowel varices are not seen on routine endoscopy and may require capsule endoscopy.

Afferents-Jejunal and ileal branches of SMV.

Efferents-The efferents of small bowel varices usually drain into veins of Retzius. The most common pathway is an ileocolic vein draining through the right gonadal vein 
either into the right renal vein or IVC. ${ }^{22}$ Occasionally, the left gonadal vein may act as an efferent for IMV varices. ${ }^{23}$

\section{Large Bowel Varices}

\section{Colonic Varices}

Common locations are cecum and rectosigmoid and mostly seen in cirrhosis or portal vein obstruction patients. Less commonly, it can be seen in congestive cardiac failure, mesenteric or splenic vein obstruction, and mesenteric vein compression. ${ }^{7,24-26}$

Afferents-SMV branches, namely, the ileocolic, right colic, and middle colic veins for the right colon and IMV braches for the remaining part of the colon.

Efferents-Drains into the veins of Retzius, which include right gonadal, right renal, or lumbar veins. ${ }^{13}$

\section{Rectal Varices}

Rectal varices and internal hemorrhoids are different entities. Rectal varices characteristically are seen above the dentate line and yield to compression in contrast to hemorrhoids. The prevalence of hemorrhoids is not increased by the presence of portal hypertension. ${ }^{27}$ Rectal varices can manifest as mild or uncontrolled bleeding per rectum.

Afferents-The superior rectal vein is a direct continuation of the IMV. Superior rectal vein further divides into extrinsic rectal venous plexus and intrinsic rectal venous plexus and both are interconnected via perforators across the muscularis propria. The superior part of intrinsic venous plexus is present in the rectal submucosa and the inferior part is present in the anal subcutaneous tissue.

Efferents-Rectal venous plexuses communicate via the rectogenital and interrectal communications and eventually drain via the middle rectal vein and inferior rectal veins into the internal iliac vein. ${ }^{28}$

\section{Umbilical Varices}

A bunch of vessels in the subcutaneous tissue of the anterior abdominal wall near the umbilicus can lead to the formation of varices. Sometimes, these can connect to varicose veins in the anterior right thigh. ${ }^{29}$

Afferents-The left branch of the portal vein via the recanalized umbilical and paraumbilical veins.

Efferents-Umbilical varices drain via superior and inferior epigastric veins into external iliac veins with the latter being the commonest path. Sometimes, paraumbilical veins can also drain via internal thoracic veins into the superior vena cava. ${ }^{13}$

\section{Biliary Varices}

In extrahepatic portal vein obstruction, multiple collateral veins can develop at the porta hepatis from two existing venous plexuses located around the extrahepatic part of the CBD. These venous plexuses are known as the paracholedochal venous plexus of Petren and the epicholedochal venous plexus of Saint. The paracholedochal venous plexus of Petren courses side by side and the epicholedochal venous plexus of
Saint courses on the surface of the $\mathrm{CBD}$ as a plexiform network. $^{30,31}$

Enlargement of these collaterals may cause portal biliopathy. Enlarged paracholedochal collaterals cause extrinsic compression of the CBD and enlarged epicholedochal collaterals cause irregularity of the mural surface of the $\mathrm{CBD} .^{32,33}$ Sometimes, biliary varices can cause hemobilia or life-threatening hemorrhage. ${ }^{34}$

\section{Stomal Varices}

Sometimes, varices can develop in the stomal mucosa especially at ileostomies following proctocolectomy for inflammatory bowel disease. ${ }^{35}$ The apposition of bowel and abdominal wall brings portal and systemic circulation together allowing for portosystemic collateralization. Bleeding is due to trauma or variceal erosion.

Often stomal varices are not seen on endoscopy; therefore, high clinical suspicion along with CT imaging is necessary in obscure cases. The morbidity is often high, but mortality is usually low around 3 to $4 \%$. Simple maneuvers such as compression bandaging with or without adrenaline, packing with gelatine foam, and suture ligation often effectively stop bleeding. ${ }^{36}$

\section{Miscellaneous Infrequent Sites}

Vesical varices can develop following abdominal surgery and may present as hematuria or rarely life-threatening intraperitoneal bleed. Intraperitoneal and cutaneous varices can cause an intraperitoneal or percutaneous bleed. ${ }^{5}$

\section{Classification}

Ectopic varices are divided based on the patency of the portal system: Type a "nonocclusive or oncotic" (normal portal system or global portal hypertension) and Type b "occlusive" (occluded portal system). Again subdivided into Type 1 having only portoportal collaterals, Type 2 having primarily portoportal collaterals with few portosystemic collaterals, and Type 3 having primarily portosystemic collaterals with few portoportal collaterals as per Saad-Caldwell's classification $^{37,38}$ (-Fig. 3)

\section{Diagnosis and Site Localization}

\section{Endoscopy and Clinical Examination}

Inspection and palpation can help diagnose stomal or parastomal varices; otherwise, endoscopy is the primary modality to diagnose and localize the ectopic varices. On clinical examination or endoscopy, high-risk varices typically appear large, distended, or have features of the previous bleed such as "red and white spot." ${ }^{39}$ Some distal duodenal, jejunoileal, and colonic varices may not be seen on endoscopy. A high index of suspicion is required to diagnose ectopic varices in the case of brisk upper or lower GI bleed, especially if upper and lower GI endoscopy fails to identify the source of bleed in a patient with portal hypertension. 

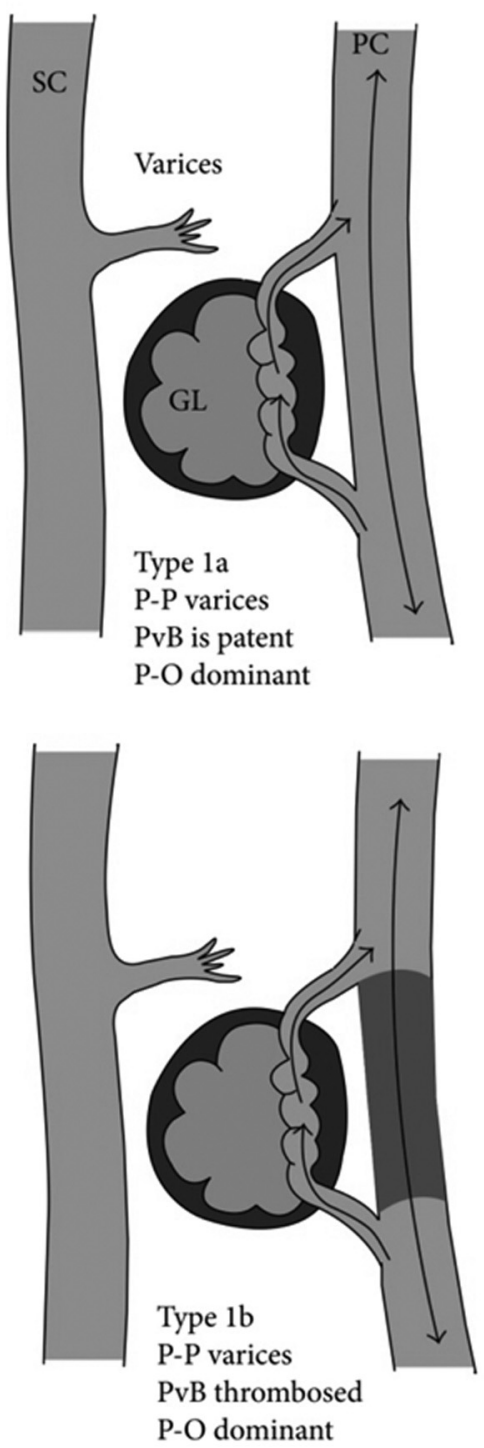
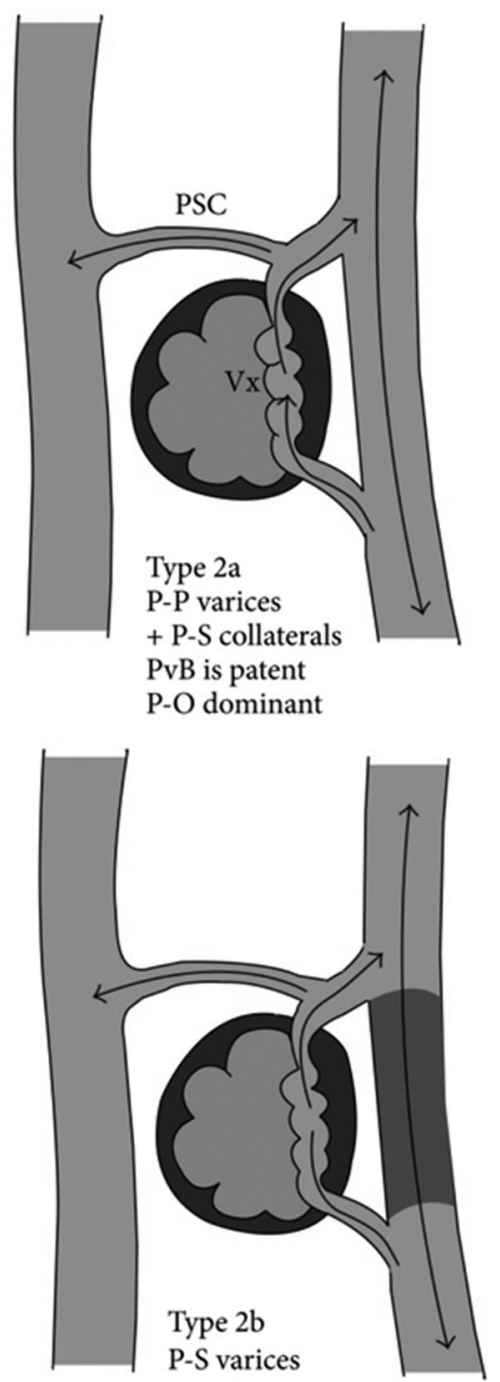

PvB thrombosed P-O dominant
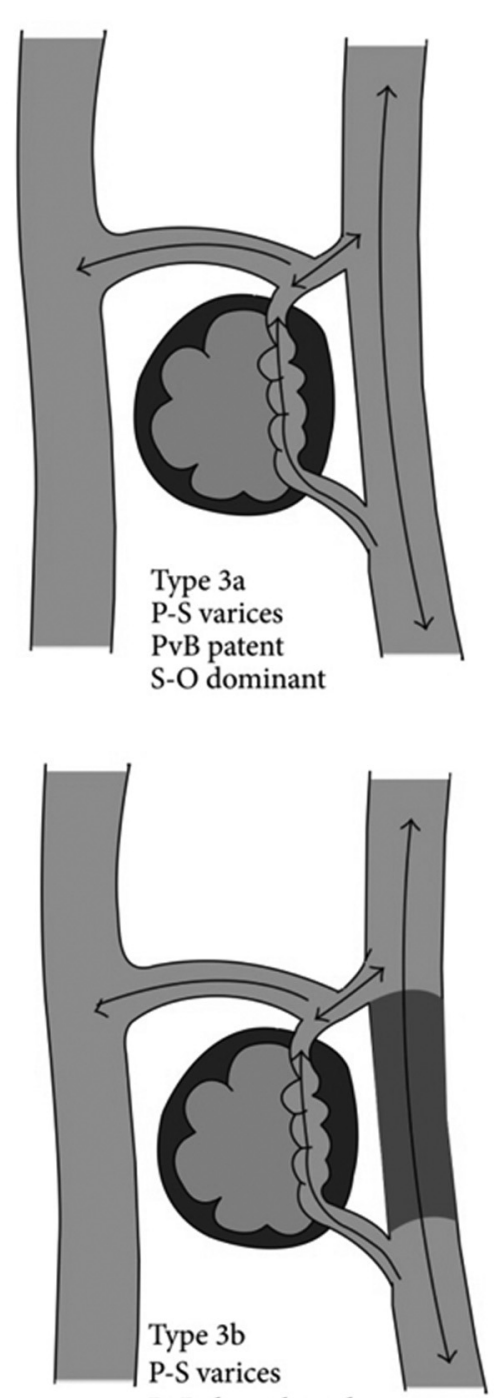

PvB thrombosed S-O dominant

Fig. 3 Hemodynamic classification of ectopic varices. PC, portal venous circulation; P-O, portal venous outflow; P-P, portoportal collaterals; P-S: portosystemic collaterals; PvB, portal vein branch; SC, systemic venous circulation; S-O: systemic venous outflow. (Reproduced with permission from Philips et al. ${ }^{37}$ )

\section{Sonography}

Doppler ultrasound effectively diagnoses patency of the entire portal venous system and direction of mesoportal blood flow which can be toward the liver, away from the liver, or fluctuating. Ultrasound has the advantage of repeatability and can be performed bedside in unstable patients.

Both diagnosis and image-guided treatment of stomal varices can be done with the help of Doppler ultrasound. ${ }^{40}$

\section{Contrast-Enhanced CT Scan}

A contrast-enhanced CT scan is the modality of choice. It helps in the diagnosis, site localization, and treatment planning of variceal hemorrhage. The 64-slice and higher slice CT scanner can quickly image even actively bleeding or hemodynamically unstable patients. Multiphasic CT allows the detection of blood loss as little as $0.5 \mathrm{~mL} / \mathrm{s}$. The raw data postprocessing and multiplaner reconstruction provide accurate anatomical detail for interventional, endoscopic, or surgical planning.

CT is effective in the diagnosis of underlying etiology such as liver cirrhosis, secondary signs of portal hypertension, or locoregional surgical causes. CT can detect extraluminal varices, particularly those located at the unusual site such as postoperative adhesions, parastomal, surgical anastomoses, or mesentery.

\section{Magnetic Resonance Imaging}

T2-weighted or postcontrast T1-weighted magnetic resonance imaging (MRI) can be used. MRI can be helpful in patients with hepatorenal syndromes where a contrastenhanced CT cannot be done. 


\section{Management}

There is a lack of randomized trials or guidelines for ectopic varices management. The management depends on the location of hemorrhage, the severity of hemorrhage, institutional expertise, and the etiology of portal hypertension. A collaborative team approach of intensivists, endoscopists, vascular interventional radiologists, and GI surgeons is desirable.

Medical, endoscopic, and surgical management are beyond the scope of this article. Here, we will elaborate on endovascular interventional radiological management.

\section{Endovascular Interventional Radiological Procedures}

Multiple image-guided approaches have been extensively reported. A very practical algorithm is mentioned by Saad et al based on etiology and patency of mesoportal circulation to guide the treatment ${ }^{38}$ ( $\mathbf{- F i g . 4}$ ).

\section{Decompression by Transjugular Intrahepatic Portosystemic Shunt}

In cirrhosis with patent portal system, transjugular intrahepatic portosystemic shunt (TIPS) has a role in the management of bleeding ectopic varices. ${ }^{41}$ Here, it is important to note that adequate ectopic varix decompression is not achieved at the usual $12 \mathrm{~mm} \mathrm{Hg}$ gradient reduction because ectopic varices decompress through many different path- ways. TIPS creation should be combined with embolization or sclerotherapy to prevent rebleed ${ }^{42}$ (- Fig. 5).

Whether to use the TIPS approach or not depends on the experience of the interventional radiologist and the severity of the underlying liver disease, in terms of Model for EndStage Liver Disease score or encephalopathy. Contraindications for creating TIPS are detailed in - Table $2 .^{43}$

Table 2 Absolute and relative contraindications of creating TIPS

\begin{tabular}{|l|l|}
\hline Absolute & Relative \\
\hline $\begin{array}{l}\text { Primary prevention of } \\
\text { variceal bleeding }\end{array}$ & Hepatoma, particularly if central \\
\hline $\begin{array}{l}\text { Severe congestive } \\
\text { heart failure }\end{array}$ & Obstruction of all hepatic veins \\
\hline Tricuspid regurgitation & Hepatic encephalopathy \\
\hline Multiple hepatic cysts & Significant portal vein thrombosis \\
\hline $\begin{array}{l}\text { Uncontrolled systemic } \\
\text { infection or sepsis }\end{array}$ & $\begin{array}{l}\text { Severe uncorrectable } \\
\text { coagulopathy (INR }>5 \text { ) }\end{array}$ \\
\hline $\begin{array}{l}\text { Unrelieved biliary } \\
\text { obstruction }\end{array}$ & $\begin{array}{l}\text { Thrombocytopenia } \\
\text { (<20,000 platelets/mm }{ }^{3} \text { ) }\end{array}$ \\
\hline $\begin{array}{l}\text { Severe pulmonary } \\
\text { hypertension }\end{array}$ & $\begin{array}{l}\text { Moderate pulmonary } \\
\text { hypertension }\end{array}$ \\
\hline
\end{tabular}

Abbreviations: INR, international normalized ratio; TIPS, transjugular intrahepatic portosystemic shunt.

\section{ECTOPIC VARICES}

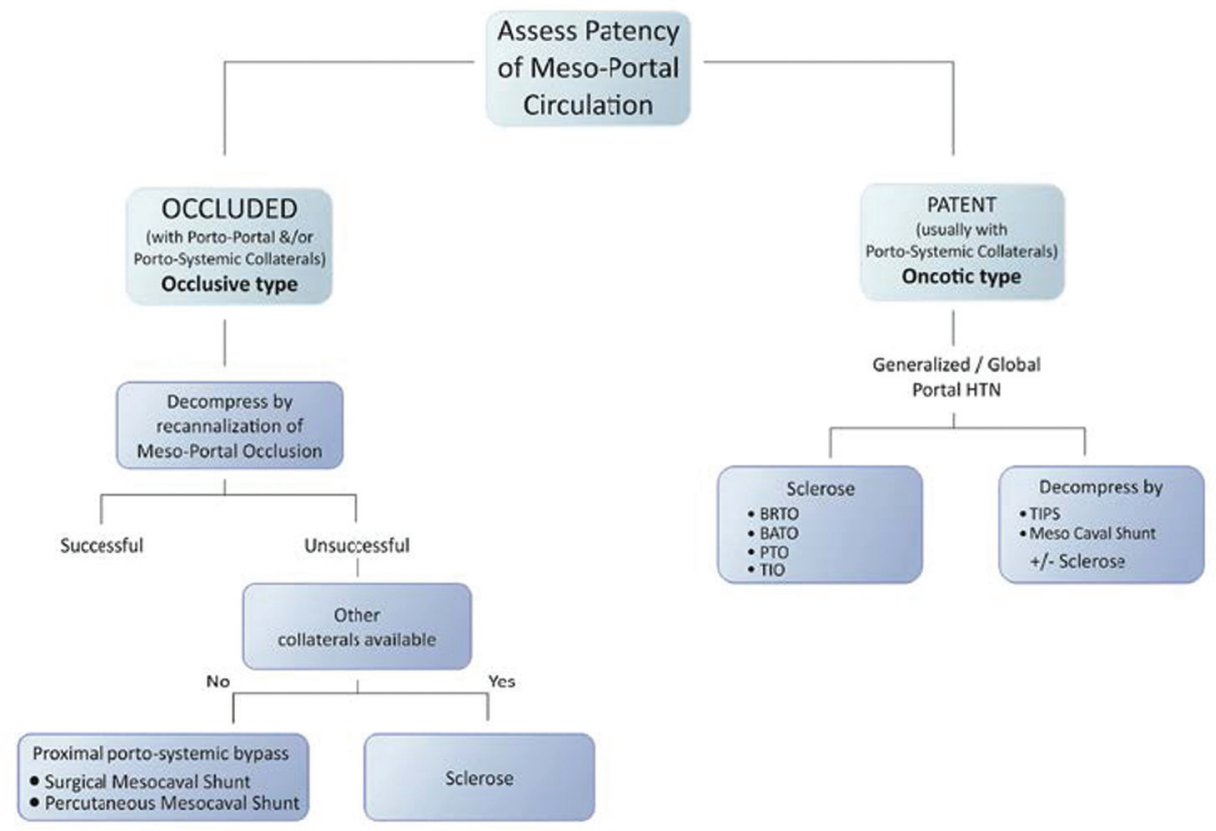

Fig. 4 Algorithm for endovascular management of ectopic varices based on hemodynamic classification by Saad et al. BATO, balloon-occluded antegrade transvenous obliteration; BRTO, balloon-occluded retrograde transvenous obliteration; PTO, percutaneous transhepatic obliteration; $\mathrm{TIO}$, transileocolic vein obliteration. (Adapted from Saad et al. ${ }^{38}$ ) 

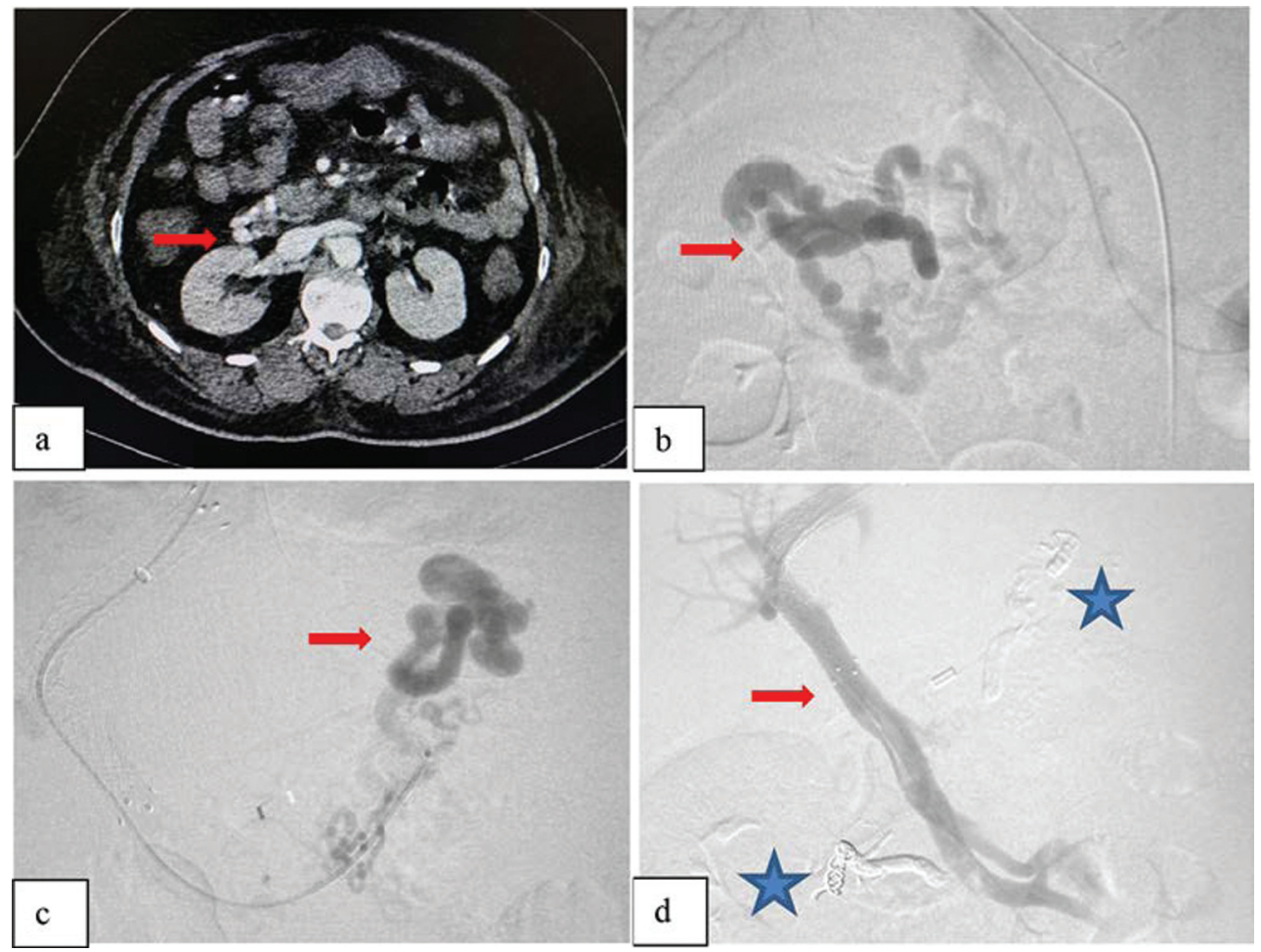

Fig. 5 A case of an elderly man with cirrhosis and portal hypertension presented with an upper GI bleed. (a) Contrast-enhanced CT in the portal phase shows duodenal varices (red arrow). (b) Portogram during the TIPS procedure shows duodenal varices (red arrow). (c) Portogram shows gastric varices (red arrow). (d) The patient was treated by coil and nbca embolization of gastric and duodenal varices with TIPS creation. Portogram shows TIPS shunt (red arrow) and the cast of nbca and coils $\left({ }^{*}\right)$. CT, computed tomography; Gl, gastrointestinal; nbca, n-butyl cyanoacrylate; TIPS, transjugular intrahepatic portosystemic shunt.

Even if decompression is contraindicated, a TIPS approach can still provide direct access to varices for sclerotherapy. One may avoid putting a stent graft, can reduce the shunt, or reverse if the need arises. ${ }^{5}$

\section{Decompression by Portal or Mesenteric Vein Recanalization}

If there is occlusion of portomesenteric circulation, then recanalization by venoplasty or stenting is a very effective decompressive strategy. Such decompression provides anatomical continuity.

The optimum decompression depends on the extent of occlusion. If limited to only the extrahepatic portal vein, then a portal vein recanalization will suffice. In case of occlusion of the confluence of the splenic and mesenteric veins, recanalization or stent placement should be done from the SMV to the portal vein and not from the splenic vein. Additional sclerotherapy of varices can be done if there is a filling of varices after decompression (-Fig. 6). Often decompression alone is enough for regression of varices ( - Fig. 7 ). In the case of splenic vein occlusion, partial splenic artery embolization can be performed also in such cases to decompress left-sided portal hypertension.

If intrahepatic portal vein branches are also occluded, then recanalized portal vein stent should be extended by TIPS to provide outflow to the portal vein to achieve an effective reduction in portal pressure. ${ }^{38}$

\section{Balloon-Occluded Retrograde Transvenous Obliteration}

When decompression is not feasible or contraindicated shunt and variceal occlusion procedures such as BRTO can be performed accessing the shunt retrogradely through the systemic venous approach. BRTO is routinely used for the treatment of gastric variceal hemorrhage with reported success rates around 89 to $100 \% .44,45$

The only contraindications to BRTO are relative (soft) contraindications. These include (1) severe uncorrected coagulopathy (which probably in this clinical setting is associated with liver failure), (2) splenic vein thrombosis (segmental portal hypertension), (3) portal vein thrombosis, and (4) uncontrolled esophageal variceal bleeding. ${ }^{46}$

There is often an improvement in hepatic function or hepatic encephalopathy because of increased portal flow to the liver. However, the resultant increase in portal pressure can cause bleeding from unsclerosed varices, the occurrence of new varices at remote sites, development of ascites, or worsening of esophageal varices. ${ }^{47}$ To minimize these problems, various additional procedures such as TIPS, ${ }^{48}$ percutaneous obliteration, and endoscopic interventions can be utilized. ${ }^{49}$

BRTO can be helpful in the management of duodenal, jejunoileal, colonic, stomal, and mesenteric ectopic varices. ${ }^{50-54}$

A mixture of air, sodium tetradecyl sulfate, and lipiodol in a 3:2:1 ratio can be used. We can also add gel foam slurry to embolize competing collaterals, accelerate thrombosis, and 


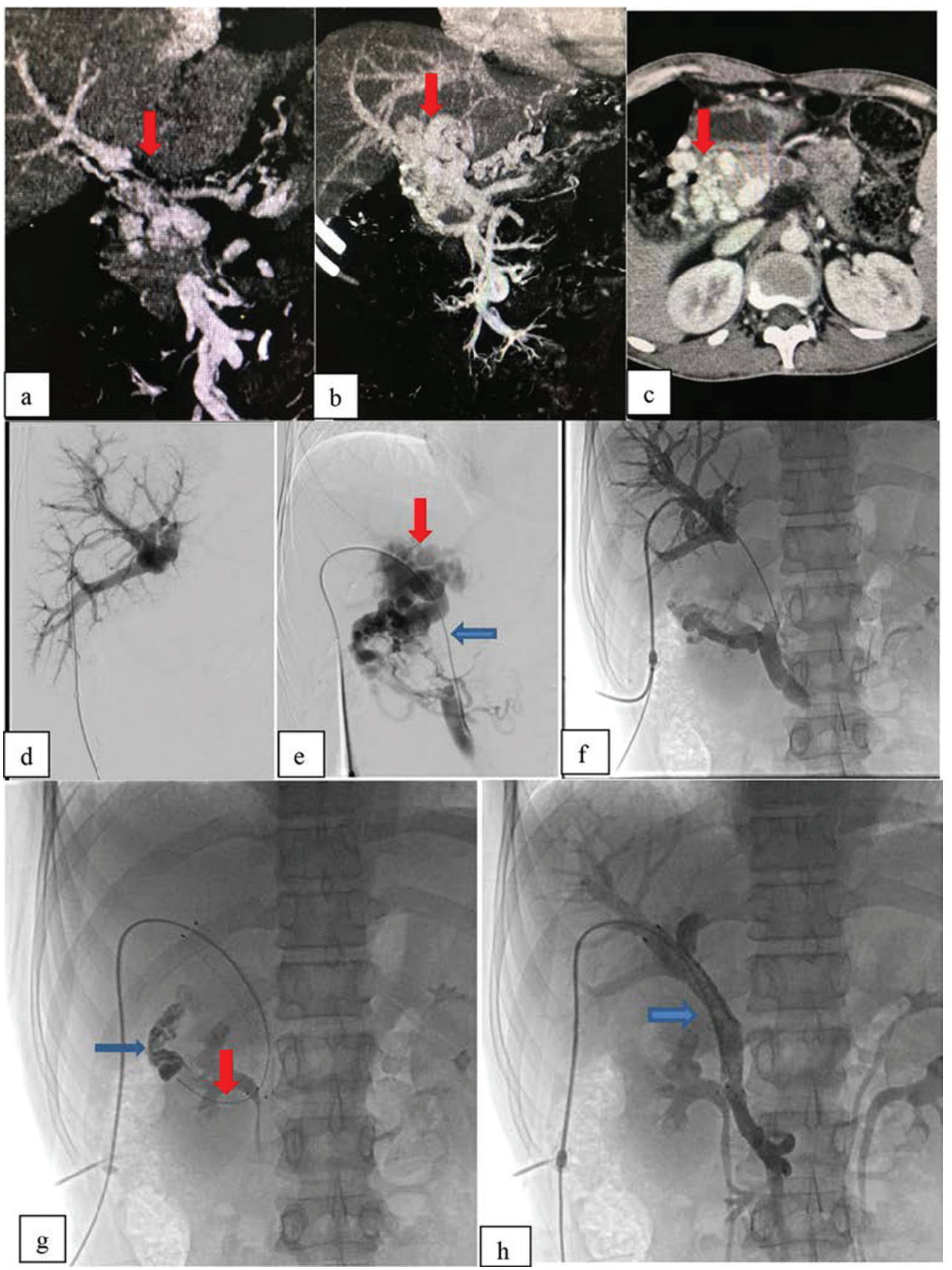

Fig. 6 A 25-year-old man presented with a recurrent upper Gl bleed. (a) CT portography coronal reformats shows occluded portal vein (red arrow). (b) Occlusion of the main portal vein with portoportal collaterals forming duodenal varices (red arrow). (c) Axial CT shows duodenal varices projecting in the lumen (red arrow). (d) Initial portogram after transhepatic access. (e, f) Portogram after crossing the occlusion shows the length of occlusion (blue arrow) and portoportal collaterals (red arrow). Portal vein stenting was done for decompression; however, collaterals were still filling, hence sclerotherapy performed $(\mathrm{g}$ ) shows the microcatheter in the collateral (red arrow) and sclerosant (blue arrow). (i) Final postprocedure portogram shows no residual stenosis and absent filling of portoportal collaterals. CT, computed tomography; Gl, gastrointestinal.

reduce sclerosant dose. We have used BRTO for ileal varices (-Fig. 8) and umbilical varices (-Fig. 9). In our experience, BRTO is a safe and effective lifesaving procedure for ectopic varices if a suitable shunt can be found for balloon navigation via a transfemoral or transjugular approach. Sometimes instead of the balloon, a modification of technique using coils called coil-assisted retrograde transvenous obliteration can be used if shunt tortuosity makes it difficult to take an occlusive balloon ${ }^{55}$ (-Fig. 10)

\section{Balloon-Occluded Antegrade Transvenous Obliteration and Direct Percutaneous Embolization} Percutaneous embolization via transhepatic route is another procedure to occlude ectopic varices with reported success 

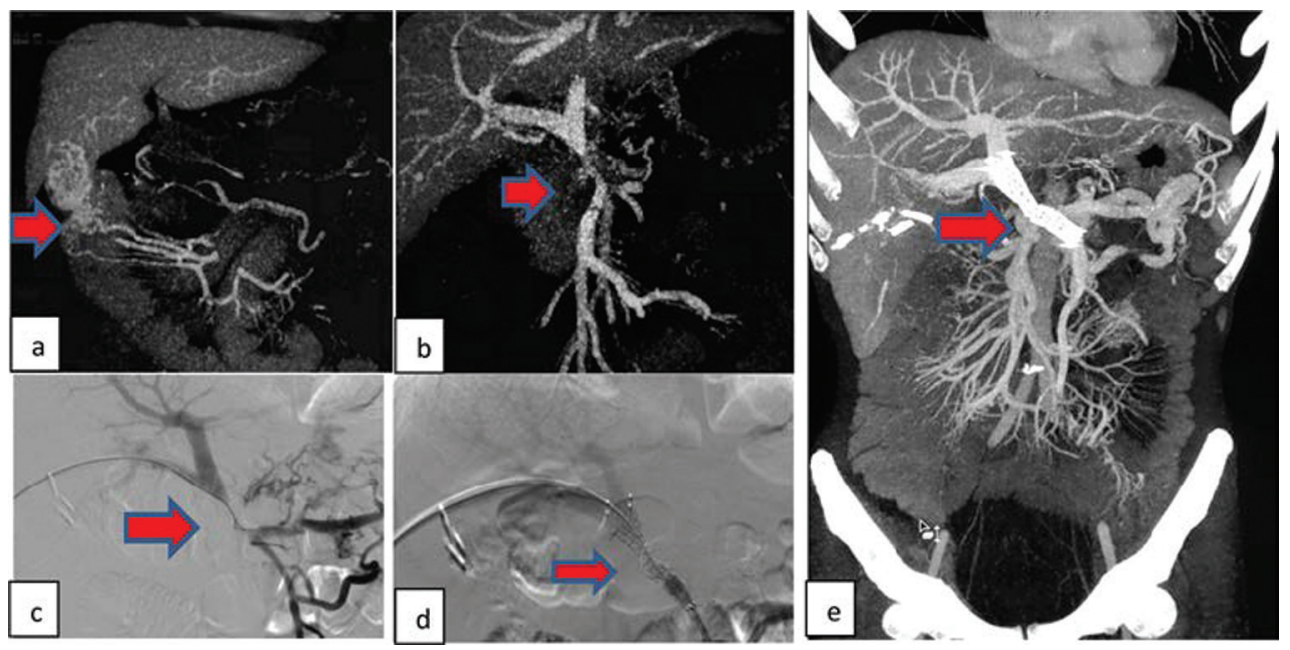

Fig. 7 Young male with pancreatic malignancy was found inoperable on laparotomy, hence surgeon performed a cholecystojejunostomy. Three months later, he presented with GI bleed. (a) Contrast-enhanced CT in portal phase shows ectopic varices in the jejunum at anastomosis site (red arrow) due to postoperative adhesions in a setting of portal hypertension secondary to splanchnic vein stenosis (b). Via transhepatic access portal and splanchnic vein recanalization and stenting was done to decompress the varices (c, d). Follow-up CT at 2 month shows complete resolution of varices with a patent stent (e). CT, computed tomography; Gl, gastrointestinal.
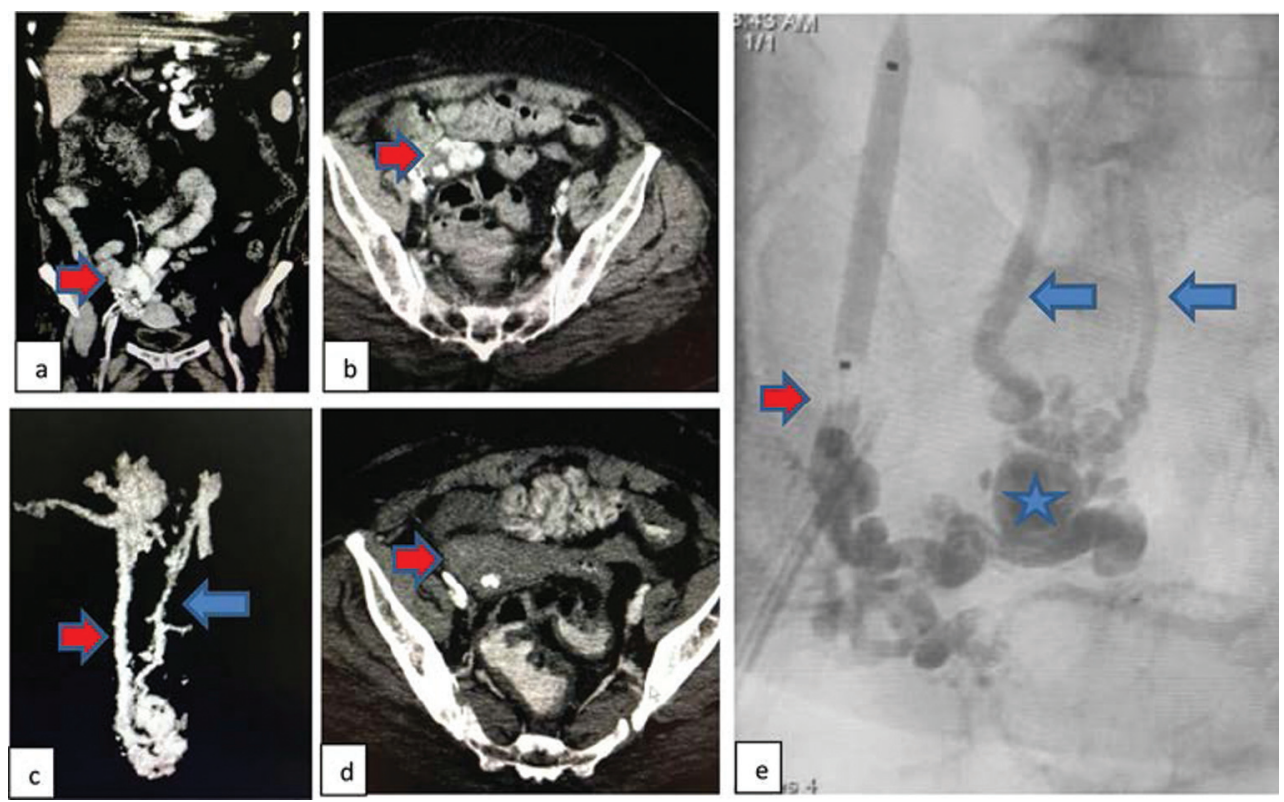

Fig. 8 A known case of an elderly woman with decompensated cirrhosis and portal hypertension presented with a lower Gl bleed and hemodynamic instability. (a) CT abdomen shows active extravasation of contrast (red arrow). (b) CT shows ectopic ileal varices (red arrow). (c) Volume-rendered image of CT portography shows afferent from ileal branches of SMV and efferent draining via a right gonadal vein into the right renal vein. Emergency BRTO was done from transjugular access. (d) Follow-up CT shows complete sclerosis of varices. (e) Image after completion of BRTO shows balloon inflated in the gonadal vein along with efferent (red arrow), varices $\left({ }^{*}\right)$, and afferent (blue arrows). BRTO, balloon-occluded retrograde transvenous obliteration; $\mathrm{CT}$, computed tomography; $\mathrm{Gl}$, gastrointestinal; SMV, superior mesenteric vein.

rates around $80 \%$ but up to $65 \%$ rebleeding rate within the next 5 months. ${ }^{56}$

The transhepatic route provides easy access to the portal system especially if the operator is not experienced for TIPS, but it has risks of tract bleeding, recurrent bleeding because of the inability of portal decompression, and is contraindicated in the presence of ascites. Sometimes, antegrade obliteration may be required using a transsplenic/transhepatic route in cases of EHPVO depending on the location and anatomy of the varices to be sclerosed.

In the case of multiple collaterals, coiling of adjacent extraluminal collaterals can be done to help create blood flow stagnation which in turn helps in increasing sclerosant contact time and prevents accidental seepage of sclerosant 

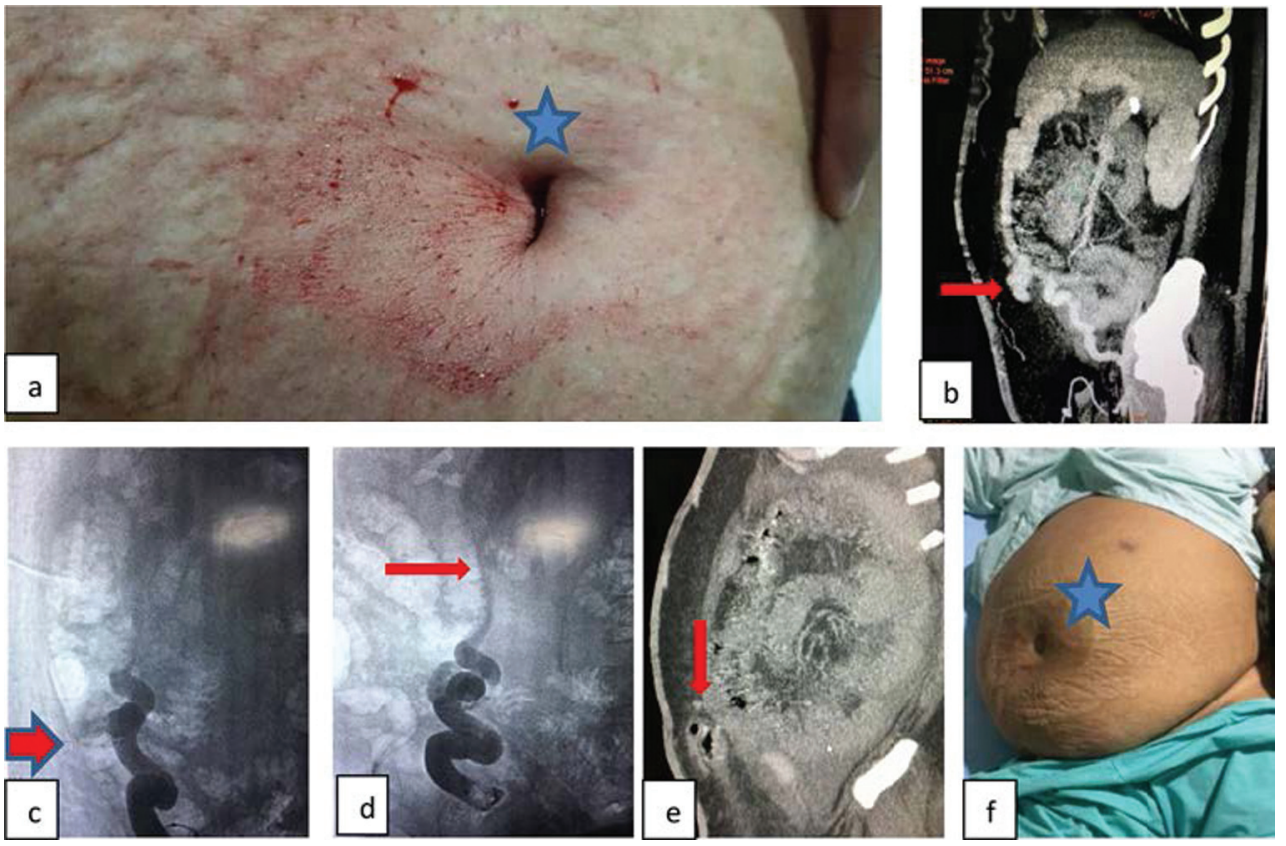

Fig. 9 Elderly morbidly obese woman with decompensated cirrhosis and portal hypertension presented with umbilical bleed. (a) Bleeding from the umbilicus (*). (b) CT shows afferent recanalized paraumbilical vein, ectopic umbilical varices (red arrow), and efferent inferior epigastric vein into the external iliac vein. (c, d) Via transfemoral access, occlusive balloon placed in shunt, and BRTO was performed using air, STDS, contrast, and gel foam combination. (e) Follow-up CT shows complete obliteration of varices with trapped air. (f) Note morbid obesity which may make surgical options quite difficult. BRTO, balloon-occluded retrograde transvenous obliteration; CT, computed tomography; STDS, sodium tetradecyl sulfate.
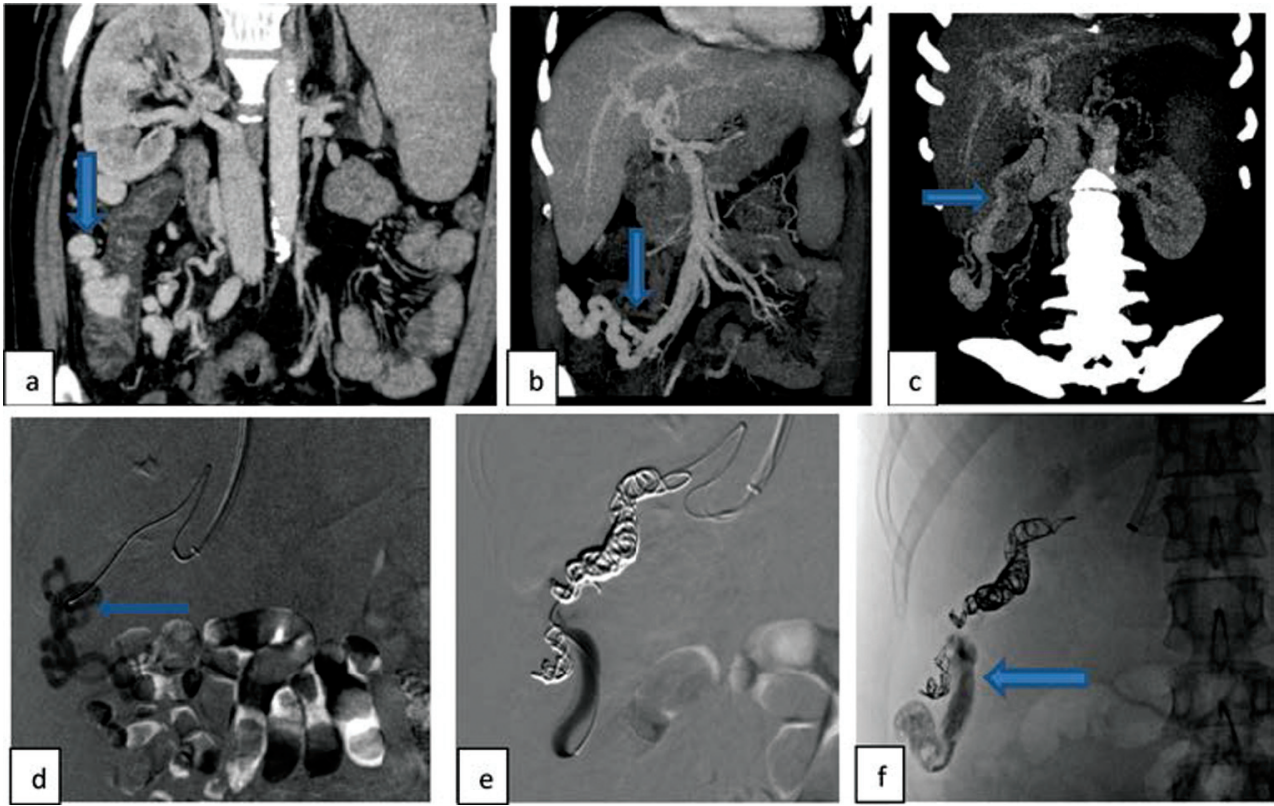

Fig. 10 Elderly man presented with a lower GI bleed. (a) CT shows the cecal varices (arrow). (b) An afferent colic branch of SMV (arrow). (c) Efferent via retroperitoneal collaterals into the right renal vein (arrow). The acute curve of the vein makes it difficult to navigate an occlusive balloon, hence CARTO was planned. (d) Microcatheter injection in the shunt (arrow). (e) Two microcatheters are navigated in the shunt, proximal one to coil the shunt and distal to inject sclerosant. (f) The total obliteration of varices was achieved (arrow). CARTO, coil-assisted retrograde transvenous obliteration; SMV, superior mesenteric vein.

on to the portal side (-Fig. 11). It is important to avoid putting coils in the submucosal varices as it can ulcerate in the lumen.

The afferent and efferent of stomal or parastomal varices can both be seen by ultrasound. Afferent can be accessed antegrade under ultrasound guidance using a micropuncture set. Sclerotherapy or coil embolization by direct ultrasoundguided puncture of cutaneous or stomal varices is described in the literature anecdotally. ${ }^{57}$ In the case of portal vein thrombosis where percutaneous transhepatic access to the 

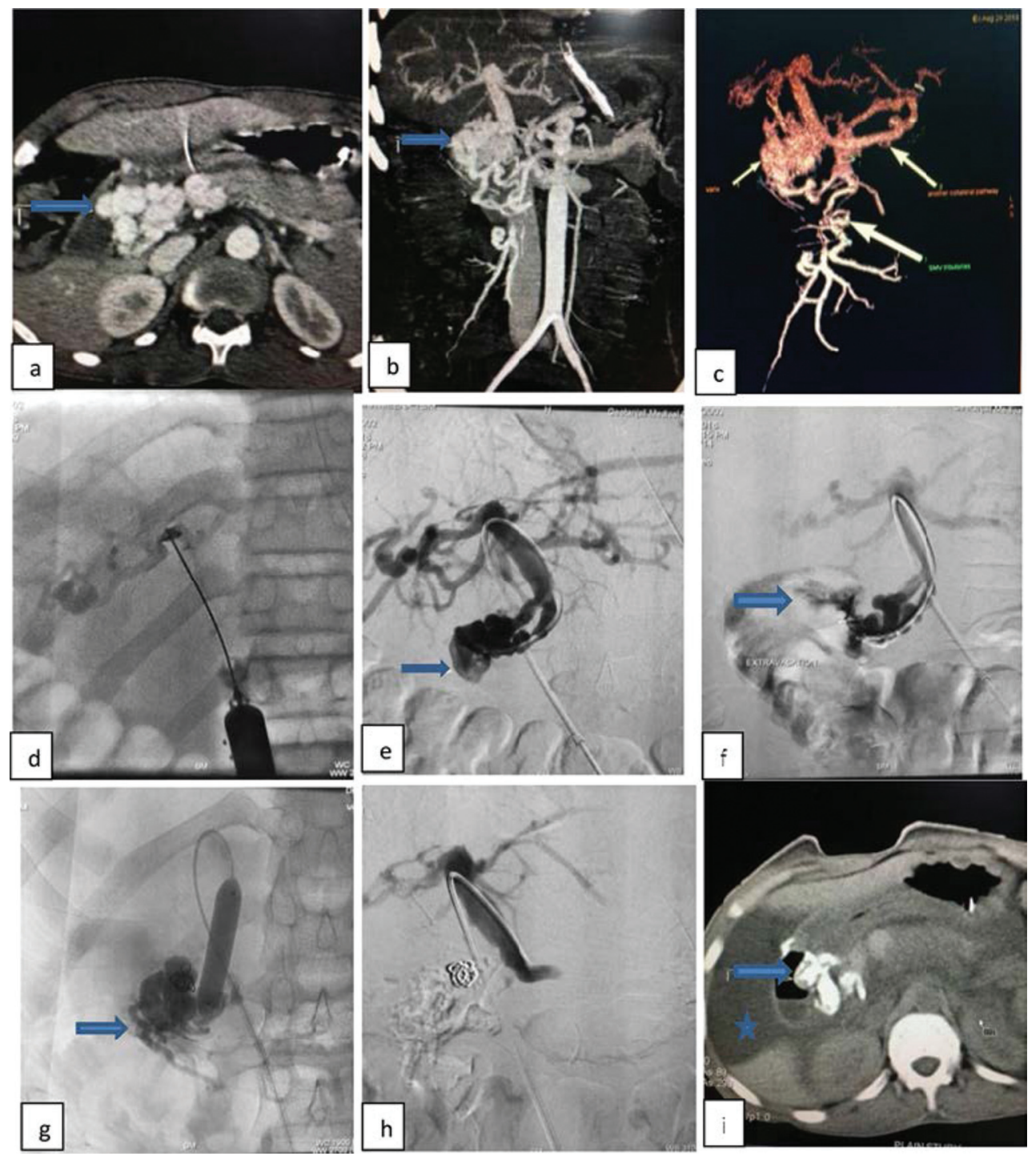

Fig. 11 A 13-year-old boy presented with an upper GI bleed. (a) CT shows EHPVO with occlusion of splanchnic veins at multiple levels and portoportal collaterals presenting as ectopic duodenal varices (arrow). (b) The intrahepatic portal vein is also occluded at multiple places (arrow). (c) Volume-rendered image shows SMV tributaries (large arrow) and two sets of collaterals (small and medium arrows) reforming the portal vein remnant. (d) Intrahepatic part of portal vein remnant accessed transhepatically. (e) Two collaterals are seen to decompress the varices (arrow). (f) Active extravasation of contrast is seen from varix (arrow). (g, h) After coiling one of the collateral to prevent spillage of sclerosant in the portal vein, BATO was done using a mixture of air, STDS, and lipiodol (arrow). (i) Follow-up CT shows complete obliteration of submucosal varix (arrow). Note ascites $\left({ }^{*}\right)$ which was not present before. This is because of the obliteration of portoportal collaterals without recanalization of the portal vein. BATO, balloon-occluded antegrade transvenous obliteration; CT, computed tomography; EHPVO, extrahepatic portal venous obstruction; GI, gastrointestinal; SMV, superior mesenteric vein; STDS, sodium tetradecyl sulfate.

portal vein is not possible, via small pararectal incision ileocolic vein can be used to access SMV or IMV. This is mainly used for sclerosis of rectal varices..$^{58}$

\section{Conclusion}

Early diagnosis of ectopic varices needs strong clinical suspicion and contrast-enhanced CT scan as endoscopy may often fail to pinpoint a source. Understanding the applied anatomy and hemodynamic classification is important to decide the most suitable therapy. Depending on the patency status of splanchnic circulation, interventional radiological procedures in the form of either decompressing the varices or obliterating them work effectively.

\section{Conflict of Interest}

None declared.

\section{References}

1 Menon KV, Kamath PS. Regional and systemic hemodynamic disturbances in cirrhosis. Clin Liver Dis 2001;5(03):617-627

2 Cichoz-Lach H, Celiński K, Słomka M, Kasztelan-Szczerbińska B. Pathophysiology of portal hypertension. J Physiol Pharmacol 2008;59(Suppl 2):231-238

3 Helmy A, Al Kahtani K, Al Fadda M. Updates in the pathogenesis, diagnosis and management of ectopic varices. Hepatol Int 2008;2 (03):322-334

4 Sarin SK, Kumar CKN. Ectopic varices. Clin Liver Dis (Hoboken) 2012;1(05):167-172

5 Akhter NM, Haskal ZJ. Diagnosis and management of ectopic varices. Int J Gastrointest Interv 2012;1:3-10 
6 Watanabe N, Toyonaga A, Kojima Set al.Current status of ectopic varices in Japan: results of a survey by the Japan Society for Portal Hypertension. Hepatol Res 2010;40(08):763-776

7 Feldman M Sr, Smith VM, Warner CG. Varices of the colon. Report of three cases. JAMA 1962;179:729-730

8 Iredale JP, Ridings P, McGinn FP, Arthur MJ. Familial and idiopathic colonic varices: an unusual cause of lower gastrointestinal haemorrhage. Gut 1992;33(09):1285-1288

9 Zaman L, Bebb JR, Dunlop SP, Jobling JC, Teahon K. Familial colonic varices-a cause of "polyposis" on barium enema. Br J Radiol 2008; 81(961):e17-e19

10 Kochar N, Tripathi D, McAvoy NC, Ireland H, Redhead DN, Hayes PC. Bleeding ectopic varices in cirrhosis: the role of transjugular intrahepatic portosystemic stent shunts. Aliment Pharmacol Ther 2008;28(03):294-303

11 Hotta M, Yoshida H, Mamada Yet al.Successful management of duodenal varices by balloon-occluded retrograde transvenous obliteration. J Nippon Med Sch 2008;75(01):36-40

12 Vangeli M, Patch D, Terreni Net al.Bleeding ectopic varicestreatment with transjugular intrahepatic porto-systemic shunt (TIPS) and embolisation. J Hepatol 2004;41(04):560-566

13 Sharma M, Babu CS, Garg S, Rai P. Portal venous system and its tributaries: a radial endosonographic assessment. Endosc Ultrasound 2012;1(02):96-107

14 Nardone G, Budillon G. Treatment of duodenal varices by endoscopic sclerotherapy. Gastrointest Endosc 1991;37(03):407-408

15 Stephan G. [Bleeding of duodenal varices in portal hypertension]. Bruns Beitr Klin Chir (1971) 1973;220(05):467-474

16 Ibukuro K, Tsukiyama T, Mori K, Inoue Y. Veins of Retzius at CT during arterial portography: anatomy and clinical importance. Radiology 1998;209(03):793-800

17 McAlister VC, Al-Saleh NA. Duodenal dearterialization and stapling for severe hemorrhage from duodenal varices with portal vein thrombosis. Am J Surg 2005;189(01):49-52

18 Perchik L, Max TC. Massive hemorrhage from varices of the duodenal loop in cirrhotic patient. Radiology 1963;80:641-644

19 Yeh YY, Hou MC, Lin HC, Chang FY, Lee SD. Case report: successful obliteration of a bleeding duodenal varix using endoscopic ligation. J Gastroenterol Hepatol 1998;13(06):591-593

20 Vellar ID. Preliminary study of the anatomy of the venous drainage of the intrahepatic and extrahepatic bile ducts and its relevance to the practice of hepatobiliary surgery. ANZ J Surg 2001;71(07):418-422

21 Cappell MS, Price JB. Characterization of the syndrome of small and large intestinal variceal bleeding. Dig Dis Sci 1987;32(04): 422-427

22 Kang HK, Jeong YY, Choi JHet al.Three-dimensional multi-detector row CT portal venography in the evaluation of portosystemic collateral vessels in liver cirrhosis. Radiographics 2002;22(05): 1053-1061

23 Sharma M, Rameshbabu CS. Collateral pathways in portal hypertension. J Clin Exp Hepatol 2012;2(04):338-352

24 Weingart J, Höchter W, Ottenjann R. Varices of the entire colon-an unusual cause of recurrent intestinal bleeding. Endoscopy 1982; 14(02):69-70

25 Francois F, Tadros C, Diehl D. Pan-colonic varices and idiopathic portal hypertension. J Gastrointestin Liver Dis 2007;16(03): 325-328

26 Sato T. Transabdominal color Doppler ultrasonography for the diagnosis of small intestinal and vesical varices in a patient successfully treated with percutaneous transhepatic obliteration. Clin J Gastroenterol 2010;3(04):214-218

27 Hosking SW, Smart HL, Johnson AG, Triger DR. Anorectal varices, haemorrhoids, and portal hypertension. Lancet 1989;1(8634) 349-352

28 Hollinshead WH. The rectum and anal canal. Anatomy for Surgeons. 2nd ed. Vol. 2. New York:. Hoeber Medical Division, Harper \& Row 1971:676-720
29 Jung SC, Lee W, Chung JWet al.Unusual causes of varicose veins in the lower extremities: CT venographic and Doppler US findings. Radiographics 2009;29(02):525-536

30 Petren T. The veins of the extrahepatic biliary system and their pathologic anatomic significance. Verh Anat Ges 1932; 41:139-143

31 Saint JH. The epicholedochal venous plexus and its importance as a means of identifying the common duct during operations on the extrahepatic biliary tract. Br J Surg 1961;48:489-498

32 Dan SJ, Train JS, Cohen BA, Mitty HA. Common bile duct varices: cholangiographic demonstration of a hazardous portosystemic communication. Am J Gastroenterol 1983;78(01):42-43

33 Sharma M. Bleeding after endoscopic biliary sphincterotomy. J Clin Exp Hepatol 2011;1(01):45-47

34 Chu EC, Chick W, Hillebrand DJ, Hu KQ. Fatal spontaneous gallbladder variceal bleeding in a patient with alcoholic cirrhosis. Dig Dis Sci 2002;47(12):2682-2685

35 Wiesner RH, LaRusso NF, Dozois RR, Beaver SJ. Peristomal varices after proctocolectomy in patients with primary sclerosing cholangitis. Gastroenterology 1986;90(02):316-322

36 Samaraweera RN, Feldman L, Widrich WCet al.Stomal varices: percutaneous transhepatic embolization. Radiology 1989;170 (03/01):779-782

37 Philips CA, Arora A, Shetty R, Kasana V. A comprehensive review of portosystemic collaterals in cirrhosis: historical aspects, anatomy, and classifications. Int J Hepatol 2016;2016:6170243

38 Saad WEA, Lippert A, Saad NE, Caldwell S. Ectopic varices: anatomical classification, hemodynamic classification, and hemodynamic-based management. Tech Vasc Interv Radiol 2013;16 (02):158-175

39 Saad WEA, Al-Ossaimi AM, Caldwell S. Pre- and post-BRTO imaging \& clinical evaluation: indications, management protocols \& follow-up. Tech Vasc Interv Radiol 2012;15:165-202

40 Saad WE, Saad NE, Koizumi J. Stomal varices: management with decompression tips and transvenous obliteration or sclerosis. Tech Vasc Interv Radiol 2013;16(02):176-184

41 Jonnalagadda SS, Quiason S, Smith OJ. Successful therapy of bleeding duodenal varices by TIPS after failure of sclerotherapy. Am J Gastroenterol 1998;93(02):272-274

42 Vidal V, Joly L, Perreault P, Bouchard L, Lafortune M, PomierLayrargues $\mathrm{G}$. Usefulness of transjugular intrahepatic portosystemic shunt in the management of bleeding ectopic varices in cirrhotic patients. Cardiovasc Intervent Radiol 2006;29(02): 216-219

43 Copelan A, Kapoor B, Sands M. Transjugular intrahepatic portosystemic shunt: indications, contraindications, and patient workup. Semin Intervent Radiol 2014;31(03):235-242

44 Mukund A, Chalamarla LK, Singla N, Shasthry SM, Sarin SK. Intractable hepatic encephalopathy in cirrhotic patients: midterm efficacy of balloon-occluded retrograde portosystemic shunt obliteration. Eur Radiol 2020;30(06):3462-3472

45 Mukund A, Rangarh P, Shasthry SM, Patidar Y, Sarin SK. Salvage balloon occluded retrograde transvenous obliteration for gastric variceal bleed in cirrhotic patients with endoscopic failure to control bleed/very early rebleed: long-term outcomes. J Clin Exp Hepatol 2020;10(05):421-428

46 Saad WEA, Kitanosono T, Koizumi J, Hirota S. The conventional balloon-occluded retrograde transvenous obliteration procedure: indications, contraindications, and technical applications. Tech Vasc Interv Radiol 2013;16(02):101-151

47 Choi YH, Yoon CJ, Park JH, Chung JW, Kwon JW, Choi GM. Balloonoccluded retrograde transvenous obliteration for gastric variceal bleeding: its feasibility compared with transjugular intrahepatic portosystemic shunt. Korean J Radiol 2003;4(02):109-116

48 Kim MJ, Jang BK, Chung WJ, Hwang JS, Kim YH. Duodenal variceal bleeding after balloon-occluded retrograde transverse obliteration: treatment with transjugular intrahepatic portosystemic shunt. World J Gastroenterol 2012;18(22):2877-2880 
118 Applied Anatomy, Hemodynamics, and Endovascular Management of Ectopic Varices Barath et al.

49 Takamura K, Miyake H, Mori Het al.Balloon occluded retrograde transvenous obliteration and percutaneous transhepatic obliteration for ruptured duodenal varices after operation for rectal cancer with multiple liver metastasis: report of a case. J Med Invest 2005;52(03/04):212-217

50 Sonomura T, Horihata K, Yamahara Ket al.Ruptured duodenal varices successfully treated with balloon-occluded retrograde transvenous obliteration: usefulness of microcatheters. AJR Am J Roentgenol 2003;181(03):725-727

51 Hashimoto N, Akahoshi T, Yoshida Det al.The efficacy of balloonoccluded retrograde transvenous obliteration on small intestinal variceal bleeding. Surgery 2010;148(01):145-150

52 Anan A, Irie M, Watanabe Het al.Colonic varices treated by balloon-occluded retrograde transvenous obliteration in a cirrhotic patient with encephalopathy: a case report. Gastrointest Endosc 2006;63(06):880-884

53 Minami S, Okada K, Matsuo M, Kamohara Y, Sakamoto I, Kanematsu T. Treatment of bleeding stomal varices by balloon-occluded retrograde transvenous obliteration. J Gastroenterol 2007;42 (01):91-95
54 Ono S, Irie T, Kuramochi M, Kamoshida T, Hirai S, Oka Y. Successful treatment of mesenteric varices with balloon-occluded retrograde transvenous obliteration via an abdominal wall vein. J Vasc Interv Radiol 2007;18(08):1033-1035

55 Mukund A, Anandpara KM, Ramalingam R, Choudhury A, Sarin SK. Plug-assisted retrograde transvenous obliteration (PARTO): anatomical factors determining procedure outcome. Cardiovasc Intervent Radiol 2020;43(10):1548-1556

56 Smith-Laing G, Scott J, Long RG, Dick R, Sherlock S. Role of percutaneous transhepatic obliteration of varices in the management of hemorrhage from gastroesophageal varices. Gastroenterology 1981;80(5 pt 1)1031-1036

57 Ryan W, Dako F, Cohen Get al.Direct percutaneous embolization of peristomal ileostomy varices in an emergency setting. Case Rep Radiol 2018;2018:6239183

58 Arai H, Kobayashi T, Takizawa D, Toyoda M, Takayama H, Abe T. Transileocolic vein obliteration for bleeding rectal varices with portal thrombus. Case Rep Gastroenterol 2013;7(01):75-81 